\title{
Klasifikasi Naïve Bayes pada Analisis Sentimen atas Penolakan Dibukanya Larangan Ekspor Benih Lobster
}

\author{
Kartika Sulastri \\ STMIK Pontianak; Jl. Merdeka No. 372 Pontianak, Telp (0561)735555, Fax (0561) 737777
}

\begin{abstract}
The refusal of the Maritime Affairs and Fisheries former Minister via Twitter, regarding the rollback on lobster larvae export ban has received positive and negative public feedback. These opinions addressed people's complaints that required to resolve. These opinions are difficult to be sorted out due to several obstacles such as informal or foreign languages, mother tongue, the use of symbols or abbreviations. Therefore, this study uses sentiment analysis. Public opinions were collected and processed through several stages consisted of data collection, pre-processing, Term Frequency as feature selection, Cross Validation as data split, classification with Nä̈ve Bayes, and Confusion Matrix as evaluation. Data pre-processing included normalization, word stemming, convert emoticon, convert negation, tokenizing, stopword removal, and case folding. The purpose of this study was to analyze sentiment using the Nä̈ve Bayes algorithm with five comparison ratios on data split between training and test data to achieve the highest evaluation value. The amount of data taken was 200 samples of tweets, which were consisted of 116 positive and 84 negative opinions. The study resulted in the highest evaluation where accuracy, precision, recall, and AUC hitting their peak at $72.50 \%, 88.64 \%, 62,42 \%$, and $86.50 \%$ respectively.
\end{abstract}

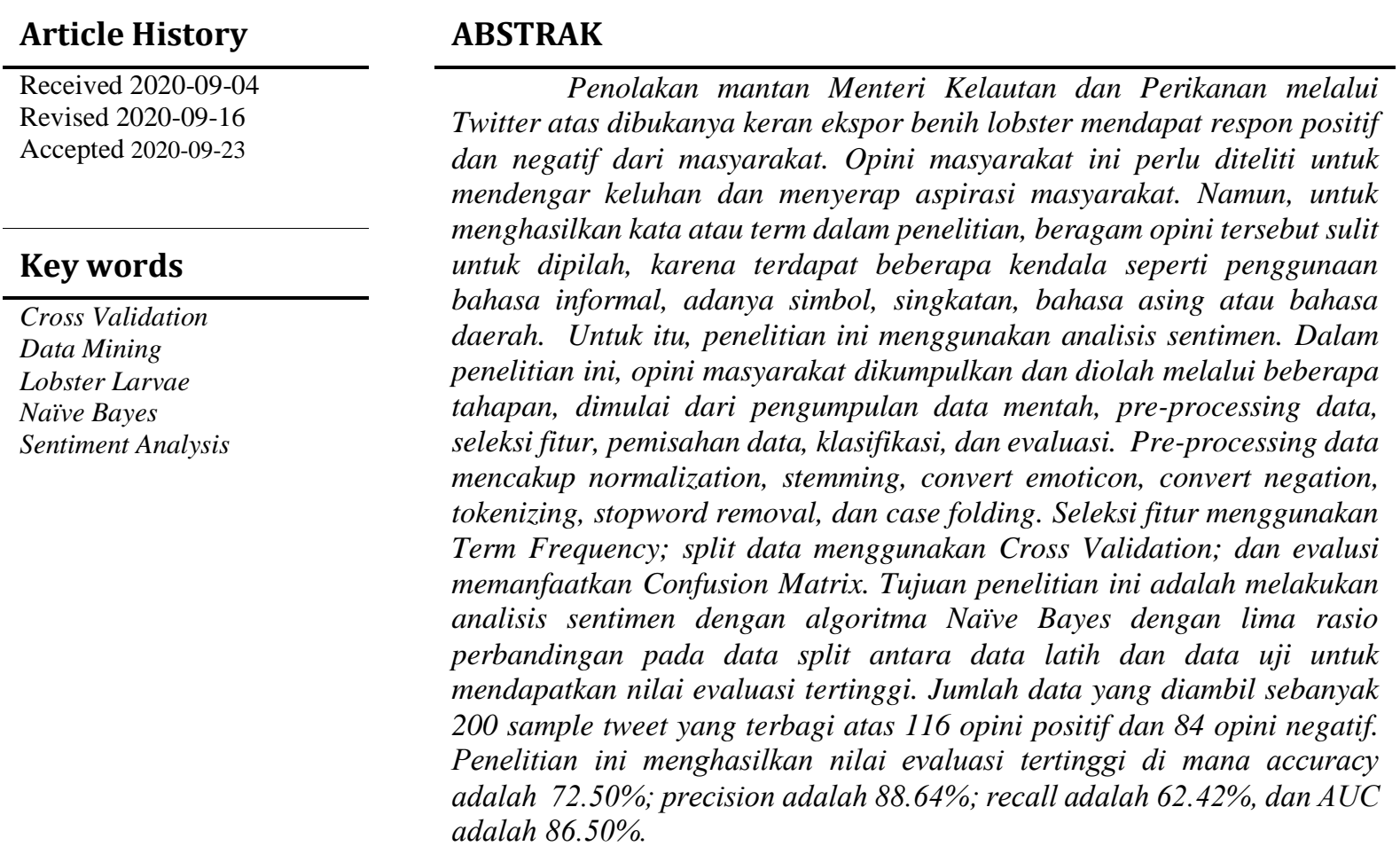

\section{PENDAHULUAN}

Pernyataan atau kritik yang dikeluarkan oleh tokoh nasional yang kontroversial selalu memunculkan pro-kontra opini masyarakat. Susi Pudjiastuti dikenal sebagai salah seorang tokoh publik yang kebijakan dan pernyataannya sering mengundang kontroversi, terutama saat ia menjabat sebagai Menteri Kelautan dan Perikanan di tahun 2014 - 2019 [1]. Saat tidak lagi menduduki posisi penting di kementerian tersebut, ia masih kerap mengkritik pemerintah. Salah satu kritik yang dilontarkan adalah tentang penolakan atas dibukanya kembali larangan ekspor benih lobster oleh Menteri penggantinya. Penolakan tersebut memunculkan beragam komentar masyarakat di media sosial. Komentar positif dan negatif tersebut dapat menjadi bahan penelitian untuk menangkap permasalahan sekaligus menyerap keinginan yang ada di masyarakat. Namun, komentar-komentar 
tersebut umumnya masih dalam bentuk yang tidak terstruktur. Hal itu dapat menimbulkan kesulitan saat pemilahan kata dalam menghasilkan komentar positif atau negatif [2]. Komentar tersebut dapat dipilah menggunakan analisis sentimen klasifikasi Nä̈ve Bayes [3].

Penolakan Susi Pudjiastuti atas dibukanya kembali keran ekspor benih lobster dilandasi beberapa alasan, antara lain kekhawatiran punahnya biota laut akibat usaha ekspor benih lobster secara masif [4]. Hal ini sesuai dengan aturan dalam PERMENKP No. 1/2015 jo PERMENKP No. 56/2016 menyatakan pembatasan hingga larangan ekspor benih lobster agar sumber daya lobster tersedia dalam jangka panjang [5]. Selain itu, upaya membatasi ekspor benih lobster supaya benih dijaga hingga menjadi lobster dewasa, agar membuka peluang meningkatkan daya saing lobster [4].

Sebelum opini masyarakat tentang pernyataan Susi Pudjiastuti diambil, diperoleh beberapa opini positif berdasarkan hasil penelitian. Eksploitasi benih lobster secara masif dikhawatirkan akan menyebabkan kepunahan [4]. Terjadinya penurunan volume ekspor akibat penurunan ketersediaan sumber daya benih lobster di tahun 2012 - 2014 [5]. Upaya budidaya lobster sangat memungkinan untuk dilakukan [6]. Lobster yang dibudidaya memiliki harga jual yang jauh lebih tinggi [4]. Sebaliknya, diperoleh opini negatif terhadap pernyataan Susi Pudjiastuti. Nelayan lebih memilih jalan pintas menjual benih lobster hasil tangkapan untuk meraup pendapatan dalam waktu cepat [6]. Nelayan merasakan kesulitan mengelola budidaya pembesaran lobster menggunakan teknologi tradisional, dengan tingkat keberhasilan tergolong rendah [4]. Teknis penangkapan lobster diakui nelayan jauh lebih efisien dan biaya operasional lebih ringan dibanding penangkapan ikan [5]. Selain itu, ketersediaan lobster di alam yang dikatakan masih mencukupi [5].

Komentar masyarakat atas kritik Susi Pudjiastuti terkait isu penolakan ekspor benih lobster muncul di berbagai media sosial, salah satunya di Twitter. Twitter adalah salah satu media sosial yang banyak digunakan masyarakat khususnya untuk menyampaikan gagasan, opini, bahkan menuangkan keluhan atau kritikan terkait suatu peristiwa [7]. Pesan yang disampaikan pengguna dalam interaksinya disebut tweet [8]. Penulisan tweet bersifat informal, dengan penambahan istilahistilah yang dipersingkat [2], [8]. Untuk itu penggunaan analisis sentimen dapat membantu mengklasifikasikan data dari opini masyarakat hingga memiliki bahasa yang terstruktur [7].

Terdapat beberapa penelitian analisis sentimen dengan klasifikasi Nä̈ve Bayes untuk mengevaluasi komentar masyarakat terhadap tokoh nasional, di antaranya analisis sentimen terkait dengan Presiden Joko Widodo [9],[10]; analisis sentimen terkait Gubernur DKI Jakarta, Anies Baswedan [11],[12]; dan analisis sentiment terkait dengan Gubernur Jawa Barat, Ridwan Kamil [13][14]. Namun, umumnya penelitian di atas lebih mengarah pada opini masyarakat terhadap sosok tokoh nasional tersebut sebagai pejabat publik. Sementara, penelitian ini menyasar pada opini masyarakat atas pernyataan tokoh nasional Susi Pudjiastuti bukan lagi sebagai pejabat publik. Fokus penelitian bertujuan untuk memperoleh nilai tertinggi hasil evaluasi analisis sentimen menggunakan Nä̈ve Bayes dengan lima rasio perbandingan pada data split antara data latih dan data uji. Perolehan 200 sampel data tweet berasal dari komentar masyarakat di Twitter [2]. Aplikasi untuk mengolah analisis sentimen menggunakan RapidMiner terbukti dapat diandalkan untuk mengolah algoritma klasifikasi Naïve Bayes [2]; dengan seleksi fitur Term Frequency; memisahkan data menggunakan Cross Validation dan evaluasi dengan Confusion Matrix [15]. Hasil akhir penelitian ini berupa nilai tertinggi evaluasi klasifikasi Nä̈ve Bayes, seleksi fitur Term Frequency, Cross Validation sebagai Data Split dengan lima rasio perbandingan antara data latih dan data uji, yaitu rasio 180:20, 175:25, 160:40, 150:50, dan 100:100 [2].

\section{TINJAUAN PUSTAKA}

\section{Analisis Sentimen}

Analisis sentimen adalah suatu ilmu dalam dunia komputasi yang mampu menjadikan data mentah tidak beraturan menjadi data yang terstruktur [15]. Beberapa bentuk data yang tidak beraturan seperti singkatan kata, penggunaan bahasa asing, bahasa daerah atau bahasa gaul, penulisan bentuk emoticon, alamat situs, dan alamat email. Analisis sentimen merupakan bagian dari data mining klasifikasi [16], di mana salah satu dari variabel suatu sekumpulan data terdapat label [17]. Dalam analisis sentimen, data diambil dari opini atau komentar individu di masyarakat dalam 
merespon suatu pernyataan yang muncul dalam bentuk teks [15]. Manfaat yang besar bagi dunia teknologi dan banyak bidang lain, khususnya untuk mengevaluasi komentar dalam kasus-kasus kontroversial, mendorong peneliti menggunakan analisis sentimen [11]. Salah satu algoritma yang digunakan dalam analisis sentimen adalah Nä̈ve Bayes [8].

\section{Naïve Bayes}

Klasifikasi Nä̈ve Bayes merupakan metode machine learning yang berasal dari teorema Bayes, yang memprediksi peluang berdasarkan pengalaman di masa lalu [8]. Metode ini menggunakan perhitungan probabilitas yang dapat diimplementasikan dengan mudah [16]. Kelebihan klasifikasi Nä̈ve Bayes antara lain metode pengklasifikasian yang sederhana [18], serta menghasilkan tingkat akurasi yang baik untuk data besar [19]. Klasifikasi Nä̈ve Bayes merupakan pembelajaran supervised. Dalam pelaksanaannya, menggunaan metode kemiripan tertinggi [8]. Klasifikasi Nä̈ve Bayes harus dilakukan menggunakan data latih yang kemudian menghasilkan model. Model tersebut diuji dengan membandingkan data uji. Hasil membandingkan tersebut merupakan nilai evaluasi yang menyatakan kualitas model yang dibuat itu bernilai lemah, sedang, baik dan sangat baik.

Klasifikasi pada Nä̈ve Bayes menghitung $\mathrm{P}(\mathrm{H} \mid \mathrm{X})$ yang bermakna peluang yang menyatakan suatu hipotesa benar pada data $X[8]$. Persamaan yang digunakan adalah sebagai berikut:

$$
\mathrm{P}(\mathrm{H} \mid \mathrm{X})=\frac{\mathrm{P}(\mathrm{X} \mid \mathrm{H}) \mathrm{P}(\mathrm{H})}{\mathrm{P}(\mathrm{X})} \quad \ldots(1)
$$

Dari persamaan di atas, $\mathrm{X}$ merupakan data pada label yang tidak diketahui. $\mathrm{H}$ menyatakan hipotesis di mana $\mathrm{X}$ merupakan label tertentu. $\mathrm{P}(\mathrm{H})$ menyatakan peluang pada hipotesa $\mathrm{H}$. $\mathrm{P}(\mathrm{X})$ menyatakan peluang data yang diteliti. $\mathrm{P}(\mathrm{H} \mid \mathrm{X})$ adalah peluang yang menyatakan bahwa hipotesis dinyatakan benar pada data $\mathrm{X}$. Sedangkan $\mathrm{P}(\mathrm{X} \mid \mathrm{H})$ adalah peluang data untuk $\mathrm{X}$, dengan asumsi hipotesa benar. Namun, data yang berupa data latih tersebut dapat diproses menggunakan klasifikasi Nä̈ve Bayes apabila telah dilakukan pre-processing.

\section{Pre-processing}

Kegiatan pre-processing terdiri dari normalization, stemming, stopword removal, tokenizing, convert negation, convert emoticon, dan case folding [2], [17]. Pre-processing ini penting untuk menyesuaikan keragaman data tweet mentah, agar selaras dengan kaidah KBBI [11]. Kata berimbuhan dikembalikan kepada kata dasar [16]. Kata yang tidak mempunyai makna ditiadakan [17]. Seluruh kata diubah menjadi huruf kecil [16]. Semua kata yang mengandung unsur negatif seperti tidak, bukan, dan jangan, diubah penulisannya menggunakan bentuk kata positif [20], dan kumpulan kata diubah menjadi satuan kata untuk dapat diproses pada kegiatan selanjutnya [3].

Setelah pre-processing, dilakukan seleksi fitur dan data split. Seleksi fitur menggunakan Term Frequency, dimana Term Frequency menghitung jumlah kemunculan setiap istilah atau kata yang muncul dalam sebuah dokumen [17]. Untuk memisahkan antara data latih dan data uji digunakan data split. Cross Validation merupakan data split yang handal dan banyak digunakan dalam penelitian. Dalam prosedur K-Fold Cross Validation, data latih dibagi menjadi K himpunan data, satu di antara bagiannya menjadi data uji. Langkah selanjutnya dilakukan iterasi sebanyak K [6]. Data latih menghasilkan model. Membuat model dilakukan dengan klasifikasi Nä̈ve Bayes. Proses evaluasi menggunakan metode Confusion Matrix. Evaluasi ini menghasilkan accuracy, precision, dan recall dan AUC. Lebih jauh, sensitivity dan specification memiliki hubungan yang saling bertolak belakang. Hubungan sensitivity dan specification dapat dinyatakan dengan ROC (Receiver Operating Characteristic Curve) [21]. Dari ROC diperoleh nilai AUC (Area Under the Curve), di mana posisi kategori hasil evaluasi dapat ditunjukkan berdasarkan nilai yang diperoleh dari $A U C$ [21]. Dalam AUC, nilai 50\%-60\% termasuk tingkat akurasi sangat lemah, nilai $60 \%-70 \%$ tingkat akurasi lemah, nilai 70\%-80\% tingkat akurasi sedang, nilai 80\%-90\% tingkat akurasi tinggi, nilai 90\%-100\% tingkat akurasi sangat tinggi [21].

\section{METODE}


Untuk memperoleh hasil dari analisis sentimen, terdapat enam langkah proses yang dapat dilakukan yaitu [2], [16]: Data set: di tahap ini data diambil dari suatu sumber, misalnya diambil dari Twitter; Pre-processing: pada tahap ini data diubah dari tidak terstruktur menjadi terstruktur; Feature selection: di tahap ini setiap kata dilakukan perhitungan pembobotan; Data split: pada tahap ini data dibagi atas data latih dan data uji; Classification: proses membuat model dilakukan; Evaluation: pada tahap ini dilakukan perbandingan antara data uji dan data model. Tahapan sistem analisis sentimen disertai dengan metode-metode yang dilakukan ditunjukkan pada Gambar 1.

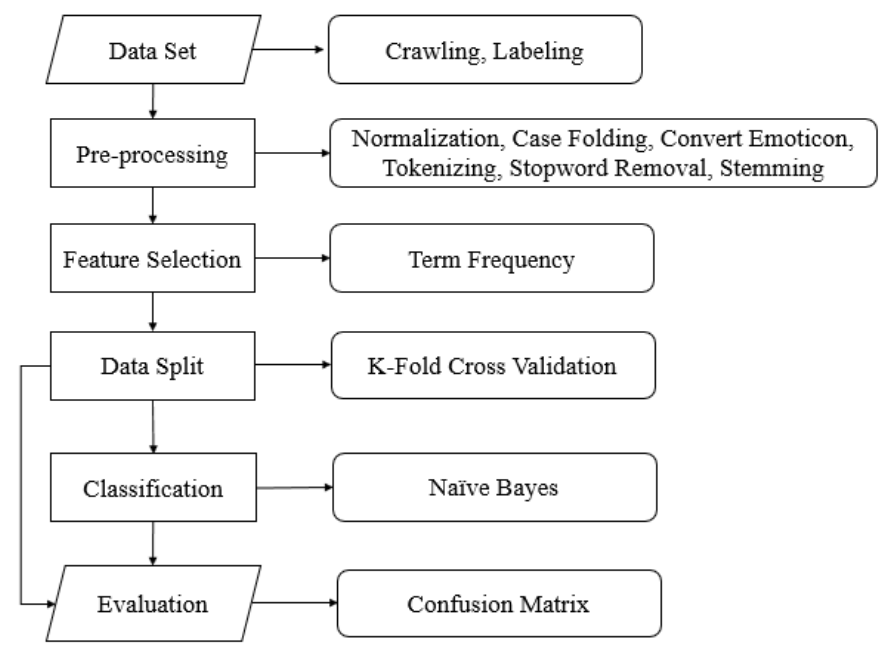

Gambar 1. Tahapan Sistem Analisis Sentimen [3], [16]

Khusus tahap klasifikasi yang dilakukan pada analisis sentimen, diketahui sekumpulan dokumen $\mathrm{D}=\{$ in $|\mathrm{I}=1,2, \ldots| \mathrm{D} \mid\}=\{\mathrm{d} 1, \mathrm{~d} 2, \ldots$ di $|\mathrm{D}|\}$ dan sekumpulan kategori $\mathrm{V}=\{\mathrm{vj} \mid \mathrm{j}=$ $1,2, \ldots|\mathrm{V}|\}=\{\mathrm{v} 1, \mathrm{v} 2, \ldots \mathrm{vn}|\mathrm{V}|\}$. Pada klasifikasi Naïve Bayes, nilai probabilitas $\mathrm{P}(\mathrm{A}=\mathrm{vj} \mid \mathrm{D}$ = di) diperoleh apabila kategori probabilitas xj diketahui. Pada setiap dokumen merupakan kumpulan dari kata-kata, seperti $<\mathrm{a} 1, \mathrm{a} 2, \ldots$, an $>$, di mana frekuensi kemunculannya merupakan variabel random. Persamaan dokumen klasifikasi dengan nilai maksimum adalah sebagai berikut:

$$
V_{M A P=} \underset{v j \in V}{\operatorname{argmax}} P(v j \mid a 1, a 2, \ldots, \text { an }) \cdots(2
$$

Argmax merupakan fungsi indeks dari nilai maksimum. Nilai $\mathrm{P}(\mathrm{vj} \mid \mathrm{a} 1, \mathrm{a} 2, \ldots$, an) pada persamaan (2) adalah sama dengan nilai $\mathrm{P}(\mathrm{H} \mid \mathrm{X})$ pada persamaan (1), sehingga persamaannya menjadi [13]:

$$
V_{M A P=} \underset{v j \in V}{\operatorname{argmax}} \frac{\mathrm{P}\left(a 1, a, 2, \ldots, a n \mid v_{\mathrm{v}}\right) P(v)}{\mathrm{P}(a, a, a, \ldots, a n)}
$$

Setelah dijabarkan, menghasilkan persamaan berikut [22]:

$$
V_{M A P=} \underset{v j \in V}{\operatorname{argmax}} P(v j) \prod_{i} P(a i \mid v j)
$$

Nilai probabilitas $\mathrm{P}(\mathrm{vj})$ pada persamaan (4) diketahui pada saat pelatihan melalui persamaan [22]:

$$
P(v j)=\frac{\mid \text { docj } \mid}{\mid \text { example } \mid}
$$

| docj $\mid$ menunjukkan banyaknya dokumen yang memiliki kategori j dalam pelatihan, sementara | example|merupakan jumlah dokumen dalam example yang digunakan untuk pelatihan. Pada akhirnya, diperoleh nilai $P(a i \mid v j)$ yang digunakan untuk menentukan probabilitas kata ai dalam kategori $j$ dengan persamaan berikut [22]:

$$
\mathrm{P}(\mathrm{ai} \mid \mathrm{vj})=\frac{n i+1}{n+\mid \text { vocabulary } \mid}
$$

Di mana ni merupakan frekuensi munculnya kata ai pada dokumen kategori vj, sementara itu $\mathrm{n}$ menyatakan jumlah seluruh kata kategori vj. | vocabulary|memperlihatkan jumlah kata pada example pelatihan.

\section{HASIL DAN PEMBAHASAN}


Dasar penelitian dimulai dari penolakan Susi Pudjiastuti di Twitter setelah Kement erian Kelautan dan Perikanan (KKP) mencabut larangan ekspor benih lobster pada tanggal 1 Juli 2020, yang diperkuat dengan tweet di tanggal 6 Juli 2020. Data diambil dari opini masyarakat di Twitter mengomentari pernyataan Susi Pudjiastuti menolak dicabutnya larangan ekspor benih lobster, dari tanggal 5 hingga 14 Juli 2020. Bahasa yang digunakan adalah disampaikan dengan menggunakan Bahasa Indonesia.

Dari data Twitter yang diperoleh, 200 sampel tweet, terdiri dari 116 tweet sentimen positif dan 84 tweet sentimen negatif.

Tabel 2. Hasil Confusion Matrix pada KFold $=2$

\begin{tabular}{lccc} 
& True Positif & True Negatif & Class Precision \\
\hline Prediksi Positif & 62 & 8 & $88.57 \%$ \\
\hline Prediksi Negatif & 54 & 76 & $58.46 \%$ \\
\hline
\end{tabular}

Hasil Evaluasi

Accuracy: $69.00 \% \pm 1.41 \%$ (micro average: $69.00 \%$ )

Precision: $88.64 \% \pm 3.58 \%$ (micro average: $88.57 \%$ )

Recall: $53.45 \% \pm 0.00 \%$ (micro average: $53.45 \%$ )

AUC: $83.10 \% \pm 0.80 \%$ (micro average: $83.10 \%$ )

Berdasarkan Tabel 2, dari 200 data uji dengan dua langkah pengujian, diperoleh hasil sebagai berikut. Total 62 data untuk klasifikasi Positif dan prediksi Positif, ada kesesuaian. Total 8 data klasifikasi Negatif dan prediksi Positif, tidak ada kesesuaian. Total 76 data untuk klasifikasi Negatif dan prediksi Negatif, ada kesesuaian. Total 54 data klasifikasi Positif dan prediksi Negatif, tidak terdapat kesesuaian.

Tabel 3. Hasil Evaluasi Confusion Matrix pada KFold $=4$

\begin{tabular}{lccc} 
& True Positif & True Negatif & Class Precision \\
\hline Prediksi Positif & 71 & 13 & $84.52 \%$ \\
\hline Prediksi Negatif & 45 & 71 & $61.21 \%$ \\
\hline & $61.21 \%$ & $84.52 \%$ & \\
\hline
\end{tabular}

Hasil Evaluasi:

Accuracy: $71.00 \% \pm 7.39 \%$ (micro average: $71.00 \%$ )

Precision: $84.24 \% \pm 5.58 \%$ (micro average: $84.52 \%$ )

Recall: $61.21 \% \pm 10.67 \%$ (micro average: $61.21 \%$ )

AUC: $85.60 \% \pm 6.20 \%$ (micro average: $85.60 \%$ )

Berdasarkan Tabel 3, dari 200 data uji dengan empat langkah pengujian, diperoleh hasil sebagai berikut. Total 71 data untuk klasifikasi Positif dan prediksi Positif, ada kesesuaian. Total 13 data klasifikasi Negatif dan prediksi Positif, tidak terdapat kesesuaian. Total 71 data untuk klasifikasi Negatif dan prediksi Negatif, ada kesesuaian. Total 45 data klasifikasi Positif dan prediksi Negatif, tidak ada kesesuaian.

Tabel 4. Hasil Evaluasi Confusion Matrix pada KFold $=5$

\begin{tabular}{lccc} 
& True Positif & True Negatif & Class Precision \\
\hline Prediksi Positif & 65 & 11 & $85.53 \%$ \\
\hline Prediksi Negatif & 51 & 73 & $58.87 \%$ \\
\hline
\end{tabular}

Hasil Evaluasi:

Accuracy: $69.00 \% \pm 9.94 \%$ (micro average: $69.00 \%$ )

Precision: $86.09 \% \pm 11.40 \%$ (micro average: $85.53 \%$ )

Recall: $55.87 \% \pm 13.21 \%$ (micro average: $56.03 \%$ )

AUC: $84.20 \% \pm 9.00 \%$ (micro average: $84.20 \%$ ) 
Berdasarkan Tabel 4, dari 200 data uji dengan lima langkah pengujian, diperoleh hasil sebagai berikut. Total 65 data untuk klasifikasi Positif dan prediksi Positif, ada kesesuaian. Total 11 data klasifikasi Negatif dan prediksi Positif, tidak ada kesesuaian. Total 73 data untuk klasifikasi Negatif dan prediksi Negatif, terdapat kesesuaian. Total 51 data klasifikasi Positif dan prediksi Negatif, tidak terdapat kesesuaian.

Tabel 5. Hasil Evaluasi Confusion Matrix pada KFold $=8$

\begin{tabular}{lccc} 
& True Positif & True Negatif & Class Precision \\
\hline Prediksi Positif & 72 & 12 & $85.71 \%$ \\
\hline Prediksi Negatif & 44 & 72 & $62.07 \%$ \\
\hline \multicolumn{4}{c}{$85.71 \%$} \\
\hline Hasil Evaluasi: & & \\
Accuracy: $72.00 \% \pm 9.07 \%$ (micro average: $72.00 \%$ ) & \\
Precision: $85.18 \% \pm 8.60 \%$ (micro average: $85.71 \%)$ & \\
Recall: $61.90 \% \pm 12.74 \%$ (micro average: $62.07 \%)$ & \\
AUC: $86.50 \% \pm 5.60 \%$ (micro average: $86.50 \%$ ) &
\end{tabular}

Berdasarkan Tabel 5, dari 200 data uji dengan delapan langkah pengujian, diperoleh hasil sebagai berikut. Total 72 data untuk klasifikasi Positif dan prediksi Positif, terdapat kesesuaian. Total 12 data klasifikasi Negatif dan prediksi Positif, tidak terdapat kesesuaian. Total 72 data untuk klasifikasi Negatif dan prediksi Negatif, terdapat kesesuaian. Total 44 data klasifikasi Positif dan prediksi Negatif, tidak ada kesesuaian.

Tabel 6. Hasil Evaluasi Confusion Matrix pada KFold $=10$

\begin{tabular}{lccc} 
& True Positif & True Negatif & Class Precision \\
\hline Prediksi Positif & 72 & 11 & $86.75 \%$ \\
\hline Prediksi Negatif & 44 & 73 & $62.39 \%$ \\
\hline \multicolumn{4}{c}{$86.90 \%$} \\
\hline Hasil Evaluasi: & $62.07 \%$ & \\
Accuracy: $72.50 \% \pm 14.19 \%$ (micro average: $72.50 \%$ ) \\
Precision: $87.02 \% \pm 15.04 \%$ (micro average: $86.75 \%$ ) \\
Recall: $62.42 \% \pm 18.14 \%$ (micro average: $62.07 \%$ ) \\
AUC: $85.30 \% \pm 0.126$ (micro average: $85.30 \%$ )
\end{tabular}

Berdasarkan Tabel 6, dari 200 data uji dengan sepuluh langkah pengujian diperoleh hasil sebagai berikut. Total 72 data untuk klasifikasi Positif dan prediksi Positif, terdapat kesesuaian. Total 11 data klasifikasi Negatif dan prediksi Positif tidak terdapat kesesuaian. Total 73 data untuk klasifikasi Negatif dan prediksi Negatif terdapat kesesuaian. Total 44 data klasifikasi Positif dan prediksi Negatif tidak terdapat kesesuaian.

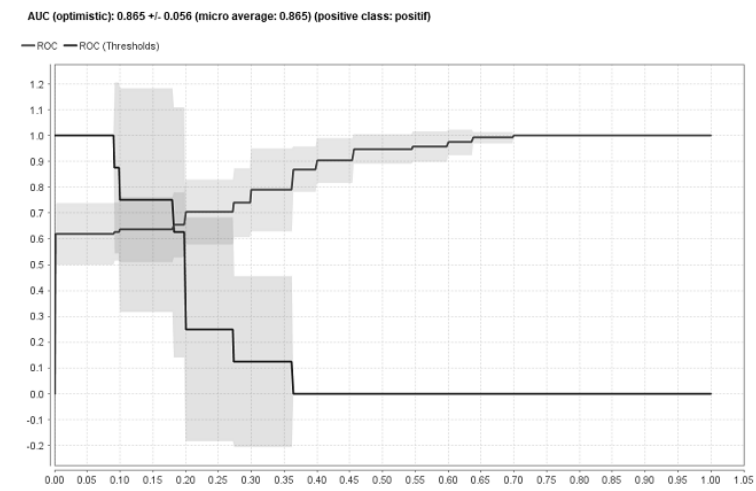

Gambar 2. AUC pada Grafik ROC 
Gambar 2 menunjukkan grafik $R O C$ dengan nilai $A U C$ tertinggi diantara KFold yang diuji. Garis horizontal merupakan nilai true positive rate, dengan rentang nilai dari 0 hingga 1.05. Sedangkan garis vertikal adalah false positive rate, dengan rentang nilai dari 0 hingga 1.2. Dari grafik tersebut, terlihat bahwa pada garis horizontal rentang nilai 0.0 hingga hampir mencapai 0.2 garis $R O C$ masih di bawah $R O C$ (thresholds), namun setelah itu garis $R O C$ semakin naik menjauh dari $R O C$ (thresholds). ROC stabil ketika mencapai garis horizontal rentang 0.7 hingga 1.0 dengan garis vertikal konstan pada nilai 1.0. Hasilnya diperoleh nilai $A U C=86.50 \%$ atau $A U C=0.865$ pada KFold $=8$.

Tabel 7. Hubungan KFold dan Hasil Evaluasi Model Algoritma Nä̈ve Bayes

\begin{tabular}{ccccccc}
\hline KFold & $\begin{array}{c}\text { Data } \\
\text { Latih }\end{array}$ & $\begin{array}{c}\text { Data } \\
\text { Uji }\end{array}$ & Accuracy & Precision & Recall & AUC \\
\hline 2 & 100 & 100 & $69.00 \%$ & $88.64 \%$ & $53.45 \%$ & $83.10 \%$ \\
\hline 4 & 150 & 50 & $71.00 \%$ & $84.24 \%$ & $61.21 \%$ & $85.60 \%$ \\
\hline 5 & 160 & 40 & $69.00 \%$ & $86.09 \%$ & $55.87 \%$ & $84.20 \%$ \\
\hline 8 & 175 & 25 & $72.00 \%$ & $85.18 \%$ & $61.90 \%$ & $86.50 \%$ \\
\hline 10 & 180 & 20 & $72.50 \%$ & $87.02 \%$ & $62.42 \%$ & $85.30 \%$ \\
\hline
\end{tabular}

Tabel 7 merupakan rangkuman dari Tabel 2 sampai dengan Tabel 6. Tabel 7 di atas menunjukkan bahwa pada kenaikan KFold, accuracy menunjukkan kenaikan dari KFold $=2$ menuju $K F$ old $=4$, kemudian mengalami penurunan pada $K F$ old $=5$, setelah itu pada $K F$ old $=8$ dan $K F$ old $=10$ mengalami kenaikan. Sementara itu, dengan kenaikan KFold, precision justru mulai mengalami penurunan, Namun, precision mengalami kenaikan secara konsisten dari KFold $=2$ menuju KFold $=10$. Begitu pula dengan recall, yang justru mengalami fluktuasi dari KFold $=2$ hingga $K F$ old $=8$, setelah itu mengalami kenaikan hingga KFold $=10$. Terakhir, kenaikan KFold, tidak berbanding lurus dengan kenaikan $A U C$.

\section{KESIMPULAN}

a. Hasil dari penelitian ini menunjukkan bahwa analisis sentimen Nä̈ve Bayes memberikan hasil dengan akurasi yang tinggi dimana nilai terendah $A U C$ adalah $83.10 \%$ dan nilai $A U C$ tertinggi adalah $86.50 \%$.

b. Semakin besar perbandingan jumlah data latih terhadap jumlah data uji cenderung meningkatkan nilai accuracy dan recall. Sementara itu, semakin besar perbandingan jumlah data terhadap jumlah data uji tidak mempengaruhi kenaikan nilai pada precision.

c. Nilai accuracy dan recall tertinggi didapat pada $K F$ old $=10$, precision tertinggi didapat pada $K F o l d=2$, sedangkan $A U C$ tertinggi pada $K F o l d=8$.

\section{DAFTAR PUSTAKA}

[1] A. H. Balkis, "Gaya Kepemimpinan Perempuan Dalam Instansi Publik: Studi Kasus Susi Pudjiastuti," J. Ilmu Adm. Negara, 2020, doi: 10.31629/juan.v8i1.2271.

[2] A. P. Natasuwarna, "Analisis Sentimen Keputusan Pemindahan Ibukota Negara Menggunakan Klasifikasi Naive Bayes,” Sensitif, pp. 47-53, 2019.

[3] A. N. Hidayat, "Analisis Sentimen Terhadap Wacana Politik Pada Media Masa Online Menggunakan Algoritma Support Vector Machine Dan Naive Bayes," J. Elektron. Sistim Inf. Dan Komput., 2015.

[4] K. Hilal, "Kepentingan Indonesia Melarang Ekspor Benih Lobster ke Vietnam Tahun 2015," Int. J. Soil Sci., 2015, doi: 10.3923/ijss.2017.32.38.

[5] F. Furqan, T. W. Nurani, E. S. Wiyono, and D. A. Soeboer, "Tingkat Pemahaman Nelayan Terkait Dengan Kebijakan Pelarangan Penangkapan Benih Lobster Panulirus spp. di Palabuhan Ratu," Albacore J. Penelit. Perikan. Laut, 2018, doi: 10.29244/core.1.3.297-308. 
[6] E. N. Susanti, R. Oktaviani, S. Hartoyo, and D. S. Priyarsono, "Efisiensi Teknis Usaha Pembesaran Lobster di Pulau Lombok, Nusa Tenggara Barat," J. Manaj. dan Agribisnis, 2017, doi: 10.17358/jma.14.3.230.

[7] P. Tyagi and R. C. Tripathi, "A Review towards the Sentiment Analysis Techniques for the Analysis of Twitter Data," SSRN Electron. J., 2019, doi: 10.2139/ssrn.3349569.

[8] F. Ratnawati, "Implementasi Algoritma Naive Bayes Terhadap Analisis Sentimen Opini Film Pada Twitter," Inovtek Polbeng - Seri Inform., 2018, doi: 10.35314/isi.v3i1.335.

[9] N. Saputra, T. B. Adji, and A. E. Permanasari, "Analisis Sentimen Data Presiden Jokowi dengan Preprocessing Normalisasi dan Stemming Menggunakan Metode Naive Bayes dan SVM,” J. Din. Inform., 2015.

[10] W. H. Silitonga and J. I. Sihotang, “Analisis Sentimen Pemilihan Presiden Indonesia Tahun 2019 Di Twitter Berdasarkan Geolocation Menggunakan Metode Naïve Bayesian Classification,” TeIKa, 2019, doi: 10.36342/teika.v9i02.2199.

[11] G. A. Buntoro, “Analisis Sentimen Calon Gubernur DKI Jakarta 2017 Di Twitter," Integer J. Maret, 2017.

[12] D. F. Budiono, A. S. Nugroho, and A. Doewes, "Twitter sentiment analysis of DKI Jakarta's gubernatorial election 2017 with predictive and descriptive approaches," 2017, doi: 10.1109/IC3INA.2017.8251746.

[13] M. S. Adhi, M. Z. Nafan, and E. Usada, "Pengaruh Semantic Expansion pada Naïve Bayes Classifier untuk Analisis Sentimen Tokoh Masyarakat," J. RESTI (Rekayasa Sist. dan Teknol. Informasi), 2019, doi: 10.29207/resti.v3i2.901.

[14] Y. T. Samuel and K. J. Manurip, "Analisis Sentimen Tokoh Publik Menggunakan Metode Naïve Bayesian Classification Pada Aplikasi Twitter," TeIKa, 2017, doi: 10.36342/teika.v7i1.2218.

[15] A. P. Kirilenko, S. O. Stepchenkova, H. Kim, and X. (Robert) Li, "Automated Sentiment Analysis in Tourism: Comparison of Approaches," J. Travel Res., 2018, doi: $10.1177 / 0047287517729757$.

[16] Mihuandayani, M., E. Feriyanto, S. Syarham, and K. Kusrini, "Opinion Mining pada Komentar Twitter E-KTP Menggunakan Naive Bayes Classifier," Semnasteknomedia Online, vol. 6, no. 1, pp. 1-2, 2018.

[17] A. F. Hidayatullah and A. SN, "Analisis Sentimen dan Klasifikasi Kategori terhadap tokoh publik pada twitter," Semin. Nas. Inform., vol. 1, no. 1, 2015.

[18] C. C. D. mining: the textbook. Aggarwal, Data Mining: The Text Book. Springer, 2015.

[19] I. H. Witten, E. Frank, M. A. Hall, and C. J. Pal, Data Mining: Practical Machine Learning Tools and Techniques. 2016.

[20] I. Zulfa and E. Winarko, "Sentimen Analisis Tweet Berbahasa Indonesia Dengan Deep Belief Network," IJCCS (Indonesian J. Comput. Cybern. Syst., 2017, doi: 10.22146/ijccs.24716.

[21] F. N. Hasan and M. Wahyudi, "Analisis Sentimen Artikel Berita Tokoh Sepak Bola Dunia Menggunakan Algoritma Support Vector Machine dan Naive Bayes Berbasis Particle Swarm Opimization," Akrab Juara, vol. 3, no. 4, pp. 42-55, 2018.

[22] M. Z. Naf'an, A. A. Bimantara, A. Larasati, E. M. Risondang, and N. A. S. Nugraha, "Sentiment Analysis of Cyberbullying on Instagram User Comments," J. Data Sci. Its Appl., 2019, doi: 10.21108/jdsa.2019.2.20. 